\title{
Critical Incident Reporting System (CIRS): a fundamental component of risk management in health care systems to enhance patient safety
}

Walter Petschnig $^{1 *}$ and Elisabeth Haslinger-Baumann ${ }^{2}$

\begin{abstract}
Background: The complexity of health care systems, the development of clinical approaches, and both scientific and technological advancements give rise to new requirements in clinical risk management. An expedient risk management is expected to deal with as many risks as possible to ensure patient safety. A prerequisite for a clinical risk management is a well-functioning error-reporting culture in health care organizations. The present study analysed the relationship between the Critical Incident Reporting System (CIRS) and patient safety. In particular, the aim of this work is to evaluate whether data from available sources provide sufficient evidence for the utility of CIRS and to derive recommendations for both theorists and practitioners. On paper, CIRS is expected to be useful in clinical settings because it allows the identification of weak spots, hazards, and critical situations such as 'near misses'. However, neither a general CIRS database based on clinical reports exists nor a universal CIRS policy or CIRS direction has been established so far, which can be attributed to the inhomogeneity of the literature and the variability of approaches. Therefore, ordering and analysis of clinical reports are highly desirable.
\end{abstract}

Methods: First, inclusion criteria, exclusion criteria, and keywords were defined to collect studies, reviews, and other sources on CIRS from official databases. After the collection of appropriate articles, a description of the individual data is given. Then, data are classified into different sections based on their respective central statements, and a brief description is given. Finally, the reports are analysed in order to detect patterns and differences.

Results: There is a close correlation between the establishment of CIRS in a health care organization and patient safety, although a quantitative relationship between reporting systems and safety is still unproven. CIRS allows the identification and implementation of appropriate actions and strategies toward patient safety. Several prerequisites were identified: top management commitment, transparency, training, anonymity, incentives, and an open error-reporting culture. Personnel have an important impact on the reduction of risk and on the development of safety. The leadership should accept the implementation of a "no blame" error and feedback culture and the security of an absolutely anonymous reporting system. The position of a risk or safety manager is highly recommended.

Conclusion: As immediate recommendations, health care organizations are encouraged to adopt CIRS. On the other hand, several research topics were identified, such as the quantitative relationship between CIRS and safety or the development of reliable incident-reporting indices and the ways on how to deal with them. Intensified empirically based research may help in answering open questions concerning CIRS.

Keywords: Critical Incident Reporting System, Clinical risks, Literature review, Patient safety, Risk management

\footnotetext{
* Correspondence: walter.petschnig@saferhealthcare.at

${ }^{1}$ Neurologisches Rehabilitationszentrum Rosenhügel, Rosenhügelstraße 192 a,

1130 Wien, Austria

Full list of author information is available at the end of the article
}

(c) The Author(s). 2017 Open Access This article is distributed under the terms of the Creative Commons Attribution 4.0 International License (http://creativecommons.org/licenses/by/4.0/), which permits unrestricted use, distribution, and reproduction in any medium, provided you give appropriate credit to the original author(s) and the source, provide a link to the Creative Commons license, and indicate if changes were made. The Creative Commons Public Domain Dedication waiver (http://creativecommons.org/publicdomain/zero/1.0/) applies to the data made available in this article, unless otherwise stated. 


\section{Background}

A pivotal task in health care systems is to provide the best possible diagnosis and treatment of specific diseases. However, an increase in complexity, both time and cost pressure, and workload in conjunction with novel medical technologies may turn health care institutions and organizations into high-risk areas, suggesting risks for patients, negative consequences for health care organizations, and an increase of cost. A study by the Institute of Medicine [1] in 1999 has shown that between 44,000 and 98,000 Americans per year are dying due to avoidable errors in medication. For the first time, medical attendance errors are placed within the list of the ten most frequent causes of death before breast cancer or traffic accidents. Therefore, it is obvious that processes and even staff in the health care sector can be regarded as a source of risk. On the other hand, based on existing ethical policies and legal regulations, health care institutions and organizations are to regain and maintain patient confidence [2]. Therefore, they have to align processes and courses of action for the benefit of patients. To avoid risky measures, the implementation of a well-developed clinical risk management in conjunction with a "no blame" mission is one of several options in this optimization process.

In Germany and Austria, a matured error-reporting culture is not fully developed [3]. The establishment of a wellfunctioning error-reporting culture in health care institutions and organizations is often hampered by staff, which can be attributed to the fear of financial and personal consequences. More transparency in risk reduction processes in health care institutions and organizations is highly desirable [4]. In this context, several issues must be addressed:

- The creation of a combined illustration of international results concerning voluntary incidentreporting systems such as the Critical Incident Reporting System (CIRS)

- Verbalization of international, European, and national risk management requirements in health care facilities

- Illustration of current quantitative and qualitative data concerning avoidable errors and frequency of errors, as well as damage to health with lethal consequence in relation to therapy and health care

The aim of this study is (i) to provide an overview on CIRS and its utility in clinical risk management; (ii) to gain insight in the institutional CIRS implementation processes, i.e. to provide a generic direction on how an efficient and sustainable adoption of CIRS in a clinical organization can be achieved; and (iii) to investigate the relationship between the CIRS application and patient safety.

\section{Methods}

Currently, neither national nor international reviews on CIRS exist. Therefore, a systematic literature review of available public sources was conducted in order to ascertain the impact of CIRS on clinical risk management and patient safety. A systematic review is expected to reduce the operator bias concerning the selection of relevant studies in comparison to a more conventional narrative literature review. The literature search was done in relevant literature databases including CINAHL, Cochrane Library, Google Scholar, MEDLINE, PubMed, and Thieme e-book library using a varying combination of German and English keywords (Table 1) between October 28, 2014, and May 25, 2015.

After this, predetermined exclusion criteria were used in order to identify and select the most relevant sources, which resulted in a core set of articles, paper, books, 'grey literature', etc. for data synthesis and analysis. In addition, the remaining abstracts of articles and full texts which were not taken into the core set were read for substantive relevance. Exclusion criteria were:

- Outdated data (sources published up to 2005). There were four exceptions, i.e. sources which contained data of general importance.

- No relationship between keywords found within the title, abstract, and content.

- Inadequate virtual studies and literature reviews (minimum requirements: introduction, applied method, reasonable results, discussion, and conclusion).

- No authorship and no date of publication.

- No content relevant to 'near misses', i.e. exclusion of sources dealing solely with 'adverse events' or 'sentinel events'.

Table 1 Keywords for literature search (inclusion criteria)

\begin{tabular}{lll}
\hline Entry & Keyword in German & Keyword in English \\
\hline I. & Incident Reporting System(e) & Incident Reporting System(s) \\
II. & CIRS & CIRS \\
III. & Patientensicherheit & patient safety \\
IV. & Beinahe-Fehler & near miss(es) \\
V. & Beinahe-Fehler-Meldungen & near miss reports \\
VI. & Freiwilliges Meldesystem & Voluntary Reporting System \\
VII. & Meldesysteme & reporting systems \\
VIII. & Melde- und Lernsysteme & reporting (and) learning \\
IX. & Patientensicherheitsstrategien & systems \\
$X$. & Fehlerberichtssysteme & patient safety strategies \\
XI. & 'Beinahe-Fehler-Meldungen- & near miss reports \\
& Effektivität' & effectiveness \\
$X$ II. & Fehler-Meldungen & error reporting \\
\hline
\end{tabular}


- Books and technical reports where the author(s) did not publish regular articles which can be found in regular databases so far.

After data collection, the articles were assigned to three categories: (i) studies and paper, (ii) reviews, and (iii) books and technical reports. The articles were searched for the following questions and issues:

(1) What was reported?

(2) Who has reported?

(3) What were the consequences about, i.e. which measures and courses of action have been taken into account and were implemented in order to improve or to resolve the risky situation, respectively?

(4) Impeding factors with respect to the acceptance, maintenance, and success of CIRS.

(5) Promotional factors with respect to the acceptance, maintenance, and success of CIRS.

(6) Relationship between CIRS and its impact on patient safety.

(7) Useful supplements on CIRS.

\section{Results}

After application of the selection criteria, 36 studies (Table 2), 6 textbooks (Table 3), and 14 technical reports (Table 4) for data synthesis and analysis came under scrutiny.

\section{What was reported?}

Most articles deal with the implementation and utilization of incident-reporting systems. Therefore, organizational culture, clinical staff, and safety issues play a major role in explanation of merits and demerits of CIRS and related reporting systems.

Many authors $[5,6]$ stated that incident-reporting systems capture only a small fraction of occurring incidents in hospitals. Reasons for non-reporting of errors are a lack of feedback, a lack of knowledge, time pressure, and underestimation of the critical incident (CI) [7]. It was found that a high incident-reporting rate correlates with a sound error and safety culture [8]. Another problem is the quality and validity of the incidents reports: CIRS indices are often skewed and ambiguous [9] or the information is often too generic [10]. To collect incident reports without in-depth analysis does not lead to a higher level of patient safety [11].

Incidents are prevalent in hospitals and can be found in nearly all clinical areas and operations. A field study from Switzerland [4] revealed that nearly half of all documented incidents (number $(N)=1.470$ ) are human errors $(49.5 \%)$. Other incidents can be ascribed to organizational settings (24.9\%), infrastructure and environment (10.8\%), and technical problems (6.2\%), amongst others $(8.6 \%)$. Another field study conducted in Italy and Romania [12] yielded the following results: in a hospital in Bucharest (Romania), most incident reports related to diagnostics (28\%), surgery (14\%), and patient falls (12\%). In Genoa (Italy), patient falls (32\%), incidents by nursing (20\%), and incidents in diagnostics (19\%) were reported, whereas in Milan (Italy), incidents by nursing (25\%) and medication regulation and administration $(21 \%)$ and incidents in diagnostic procedures $(17 \%)$ can be found. A Japanese study [13] showed that most reports were based on medication errors (2815 reports, $46.6 \%$ of a total of 6041 reports), followed by complications and errors with medical stock (1.147 errors, 19.0\%), and errors with patient falls $(826,13.7 \%)$. Here, the high number of reports was ascribed to an underdeveloped communication policy. A German analysis of 151 incidents [14] yielded the following results: 71 errors (47\%) based on organizational and communication errors, 54 reports $(35.8 \%)$ as a result of human errors, and technical errors (17 reports, 11.3\%), amongst others (9 reports, 5.9\%). Most errors were found in medication (29\%), followed by patient falls (14\%) and medical operations (15\%) [15]. The authors stated that $59 \%$ of all reported errors can be classified as preventable [14].

The occurrence of incidents with respect to organization and processes [16, 17], surgery and anaesthesia $[18-20]$, and medication $[6,20-25]$ were described, too.

\section{Who has reported?}

Although CIRS reports stem from very different clinical areas, i.e. theatre, ICU, patient falls, nursing care, and medication vide supra, CIRS and related voluntary reporting systems are predominantly used by nursery staff whereas it is rarely used by other clinical staff members, in particular physicians $[7,18,26,27]$. In one case, it was found that physicians reported adverse events mostly via the clinical risk management, while nursing staff used more often CIRS settings [26]. This observation may reflect the reluctance of clinical professionals to internalize the necessity of an error culture [28]. In order to remedy these shortcomings, the promotion of a voluntary involvement of physicians was highly recommended [15]. Anyway, many authors suggest that the success of incident-reporting systems depend on whether it is regarded as a holistic approach, i.e. CIRS must integrate into the organizational processes of the health care system [29-33] and even necessitates the commitment of top management [34].

Different studies illustrate that the handling of CIRS depends on the kind of occupants and the medical discipline. A study [13] stated that the majority of reports are generated by nurses using their own CIRS paper form. Conversely, the medical profession reports 


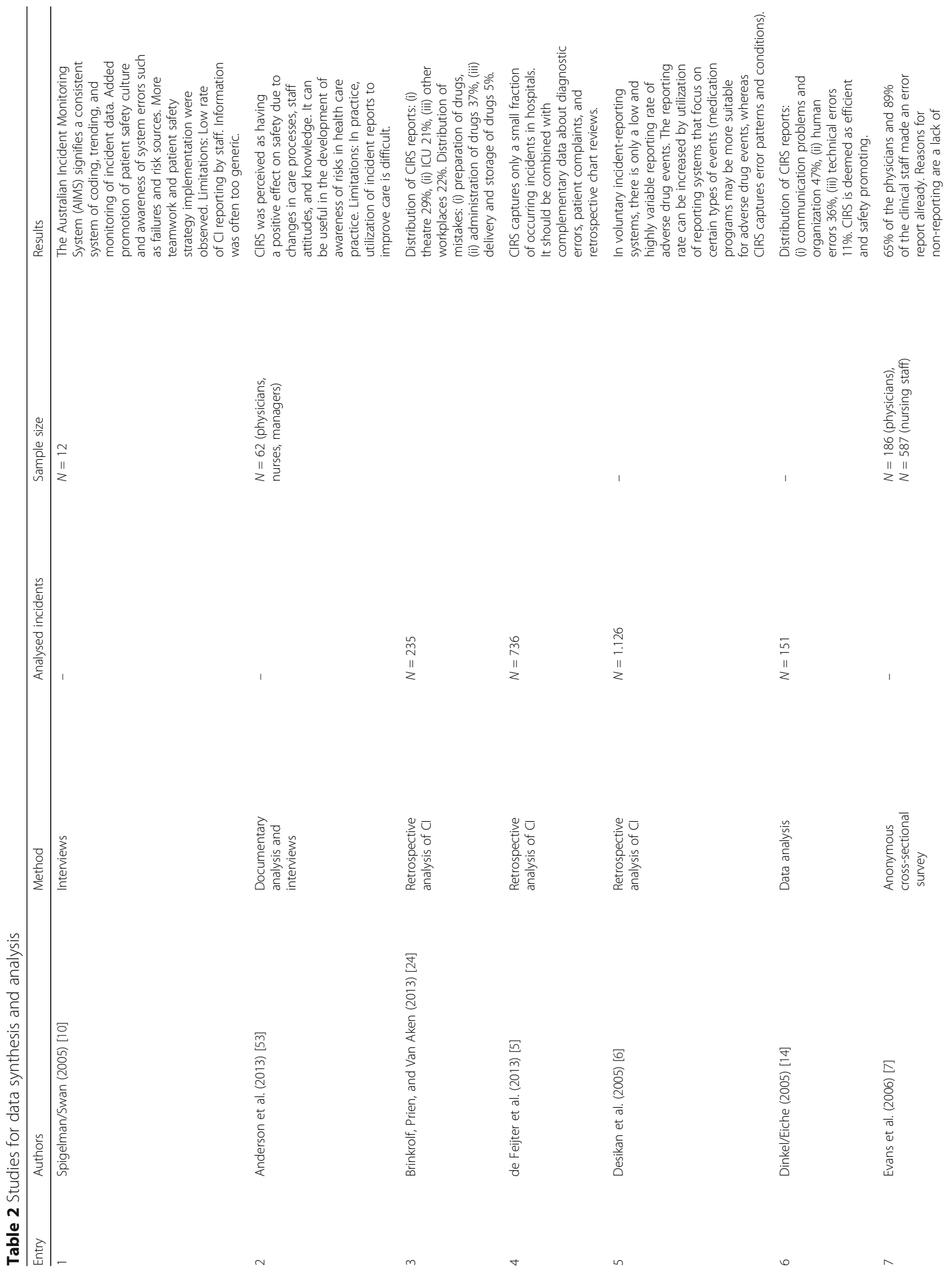






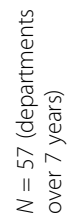

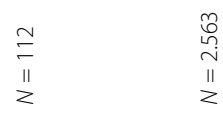

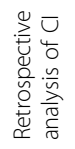



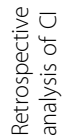
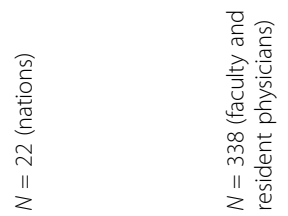

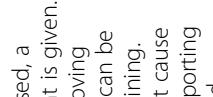

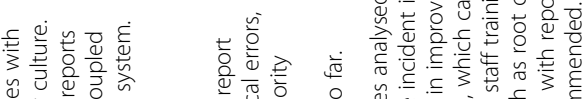

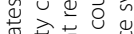

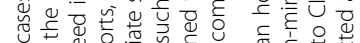

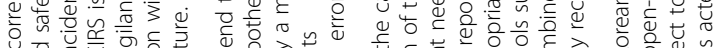

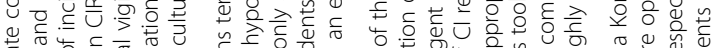

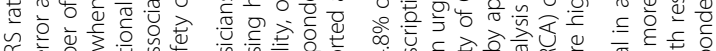

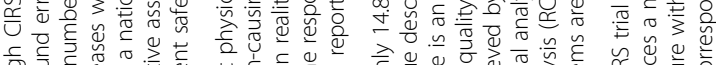

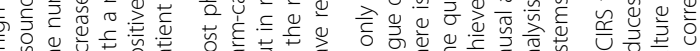




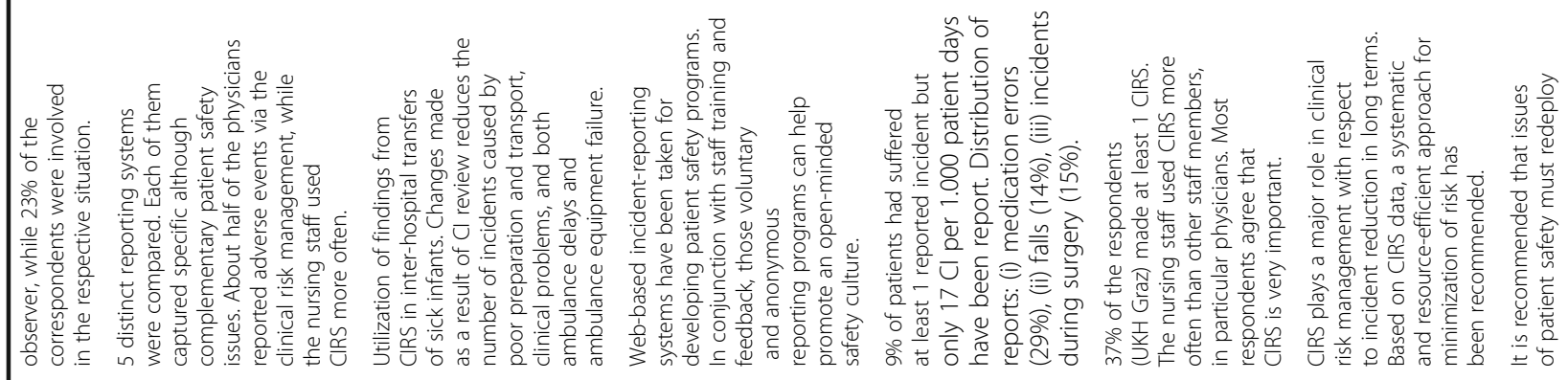

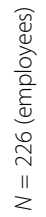

0
6
$\infty$
11
$z$

을
$\stackrel{11}{11}$
$z$

$\bar{y}$
0
0
11
$z$

$\frac{8}{11}$

$\stackrel{\infty}{\sim}$
$\stackrel{+}{+}$
II
$z$

8
$\stackrel{1}{1}$
11
$z$

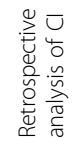

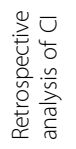



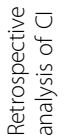

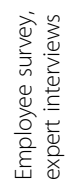

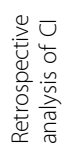






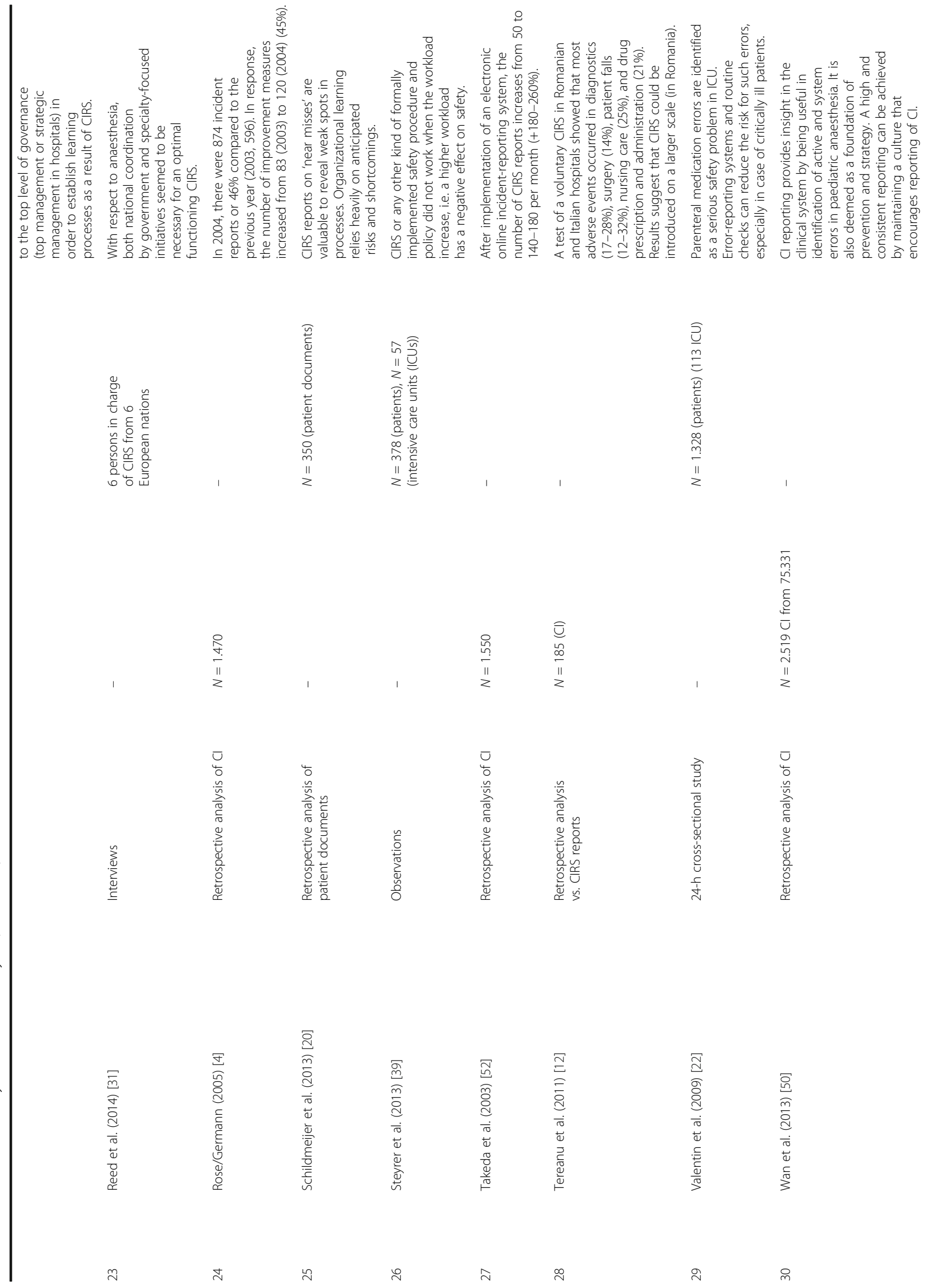




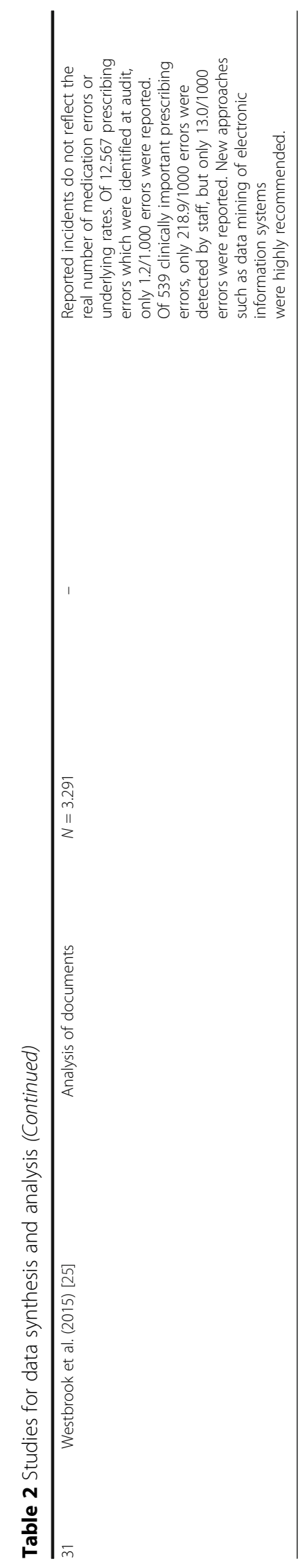




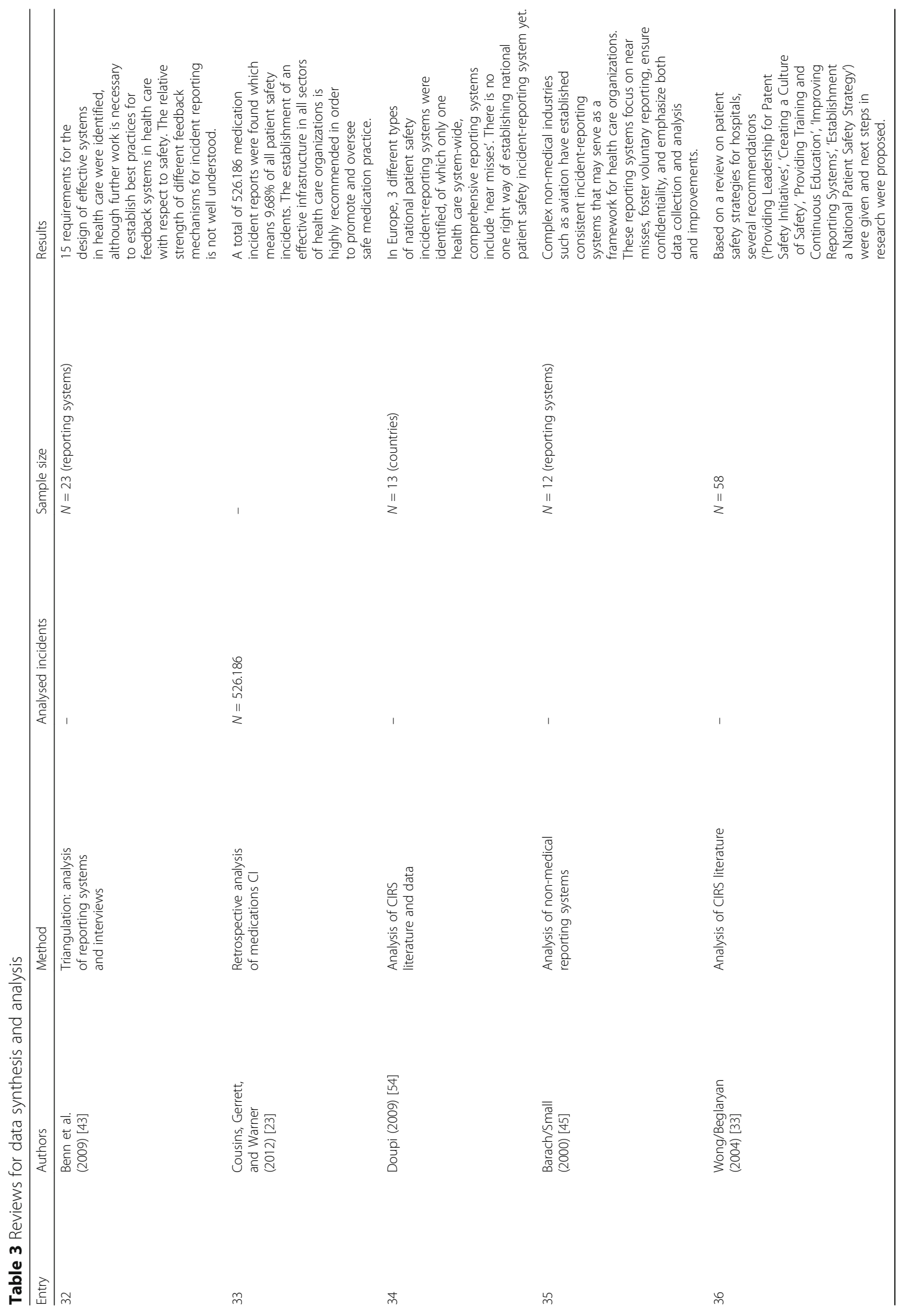




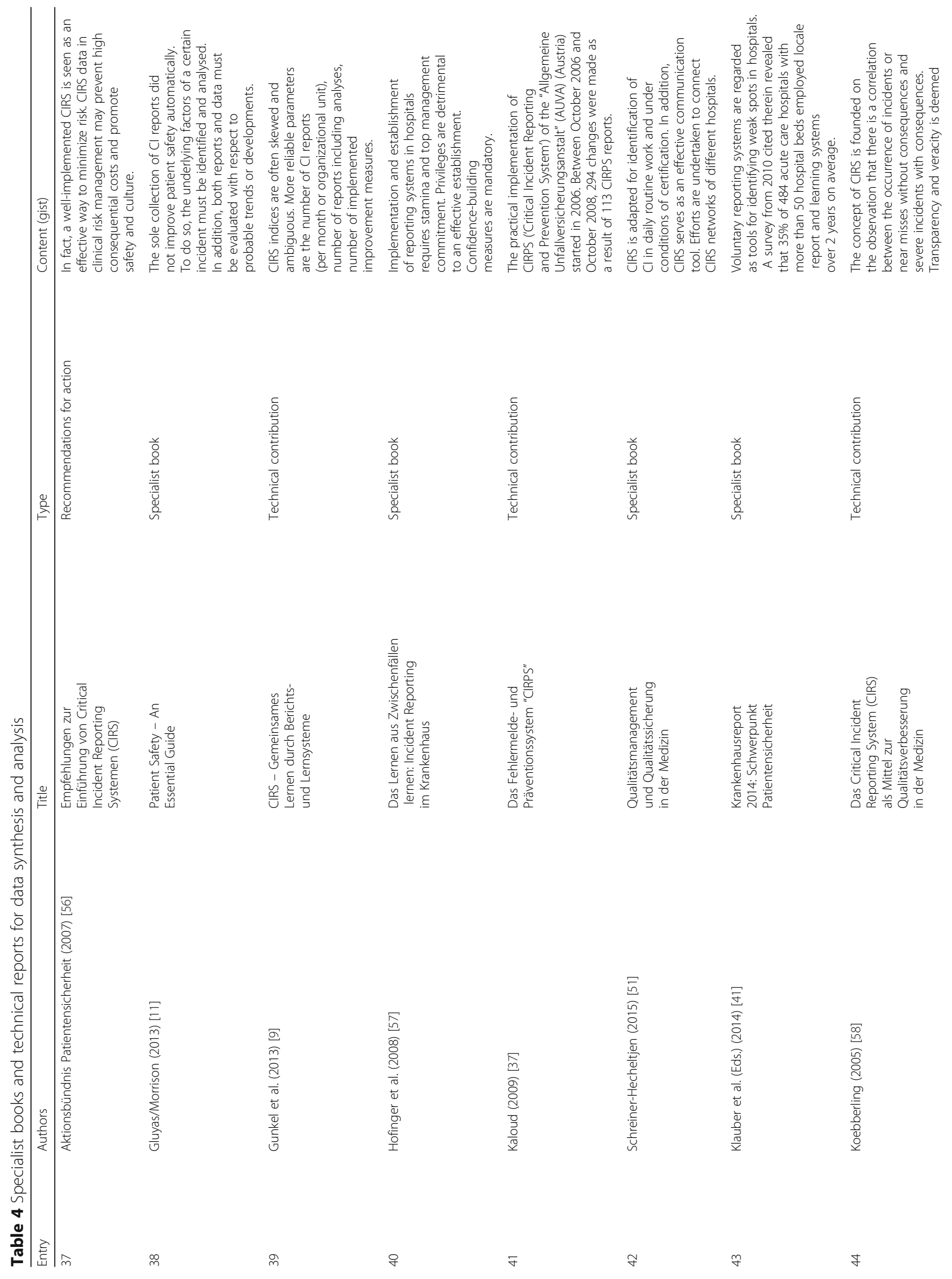




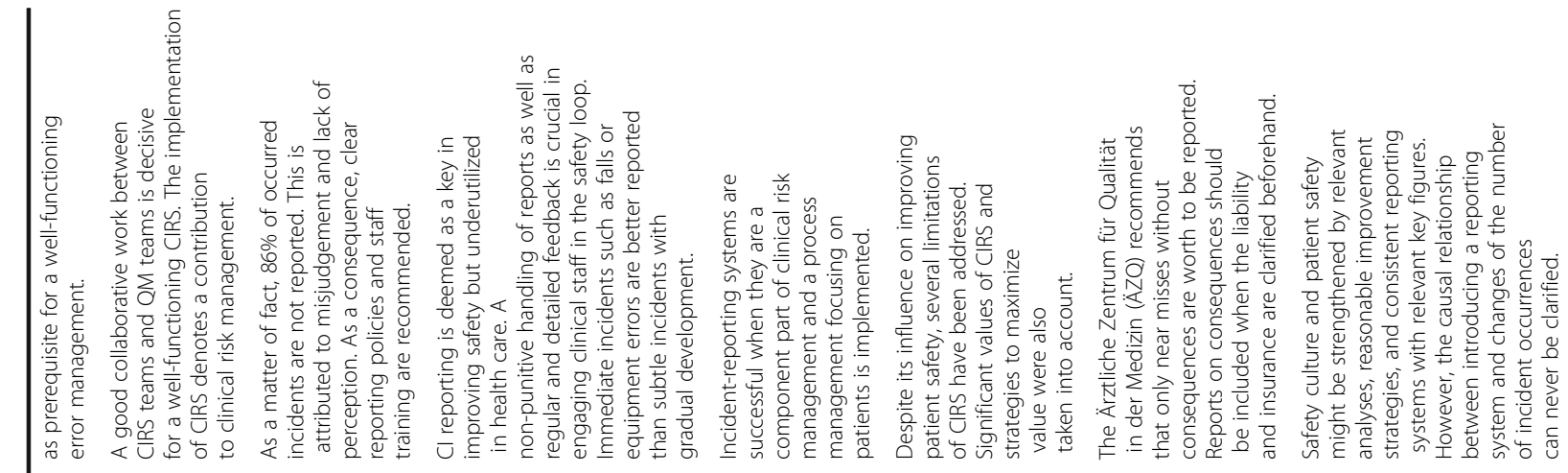

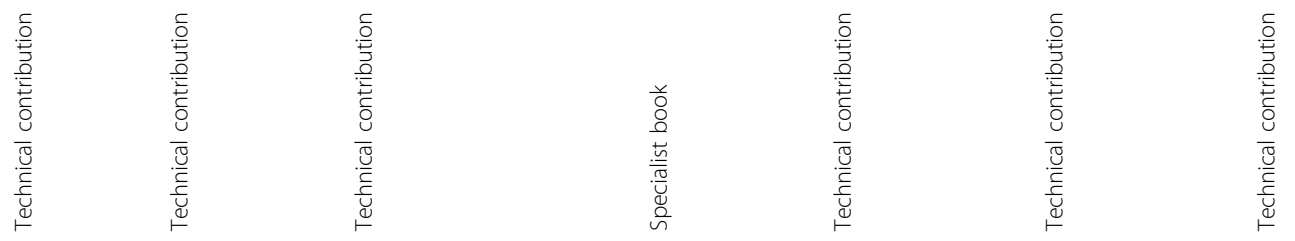

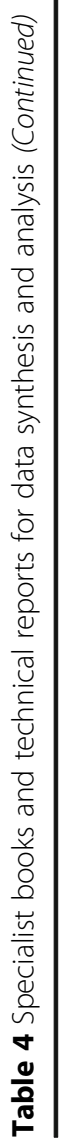
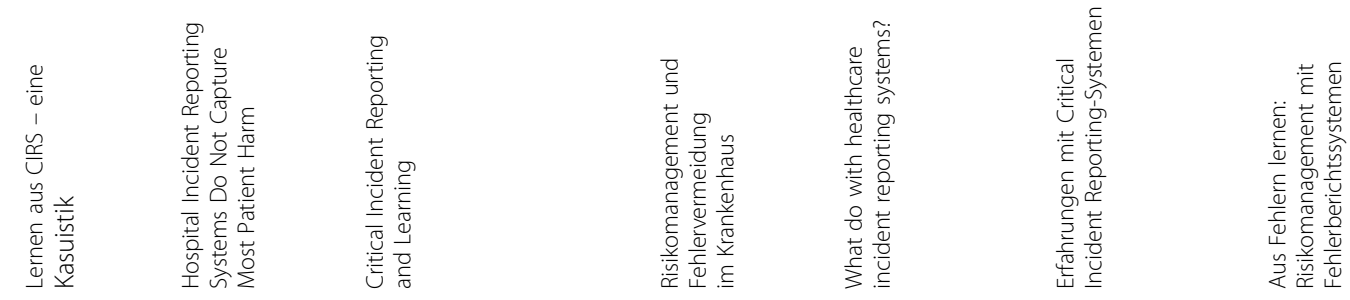

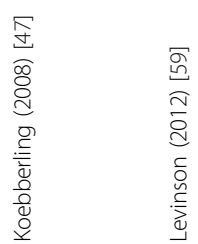



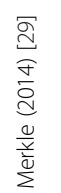

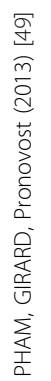

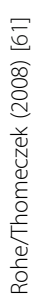

ร

\&

f

$\stackrel{\infty}{q}$

g

in

in 





preferentially clear errors. In a European study [27], about $30 \%$ of the CIRS reports $(N=226)$ stemmed from nursing personnel, about $15 \%$ from medical professionals, and about $24 \%$ from medical-technical service staff. These results are consistent with those from [35]. An analysis of different medical disciplines illustrates that mainly anaesthesia and surgical care staff use CIRS (37\%) [15]. Another source [18] revealed that mainly anaesthesia and surgical care staff report errors (37\%), followed by ward nurses (31\%), medical professionals (17\%), and administrative staff document errors (5\%). Similar results were described in a comparative study of the hospital from New York, Utah, and Colorado [15]. Here, 3407 (88\%) errors of all registered notifications were reported by the nursing staff, 73 reports $(1.9 \%)$ by physicians, and 346 reports $(8.9 \%)$ by other staff. About 50\% (1859) of all CIRS reports were submitted by the patient ward, 797 (21\%) from the intensive care units, 544 (14\%) from surgery, and less than 5\% from other areas. Other authors [15] confirmed that the minority of CIRS will be generated by medical professionals. As a consequence, they called for a more active collaboration to increase the effectiveness of reporting systems in hospitals [15].

\section{Documented improvement action}

The study of Rose and Hess [36] showed that 585 suggestions for improvement were implemented from a total of 5000 CIRS reports, although it was found that processes and measures might generate new errors. Therefore, an effective error management has to be implemented in addition to the CIRS system. In two studies, acquisition of new equipment, improvements in medication and administration, adoption of novel standards, and training programs amongst other measures were implemented as a result of incident reports [10, 37]. The training of staff was recommended by most authors. The utilization of incentives (establishment of a 'Good Catch Award') was proposed by Herzer et al. [38]. Hübler et al. [17] gave recommendations in terms of surgery and anaesthesia.

\section{Obstructive and assisting aspects}

Several factors detrimental to a well-functioning CIRS can be identified: work overload (a higher workload has a negative effect on safety [39] and/or time pressure [7]), untrained staff (ignorance or lack of knowledge amongst staff members) $[5,13,17,40]$, lack of feedback, lack of communication and/or team work [17], a poor quality of incident reports (inconclusive statements or too generic data) $[9,10]$, and the collection of incident reports without an in-depth analysis [11]. During the implementation phase of a reporting system, resentments amongst staff members which affect the acceptance of CIRS might arise [41]. With respect to the validity of the report error data and information, this can primarily be attributed to the profession [42]. Other issues were discussed in greater detail: anonymity and consequences [4], provisions and time [8, 18, 32], and feedback [7, 43].

Many authors wrote about factors that can positively affect the acceptance and effectiveness of CIRS. First of all, professional leadership is indispensable for the implementation and application of an efficient CIRS. This can be attributed to a company-specific authority and the role model function. Leadership must accept an open errorreporting culture for the safety and benefit of patients. One element is to ensure and promote effective work at all levels to increase patient safety. These can be mediated by education and training to increase the knowledge and skills of the staff $[25,27,30]$. Another aspect is the implementation of a "no blame" error and feedback culture and the security of an absolutely anonymous reporting system [4, 37, 41, 44]. Similarly, transparency, trust, and knowledge on CIRS are mandatory and are closely related to the training and skills of clinical staff [4, 14, 45-47]. In addition, feedback was identified as an essential part of CIRS $[4,13,43,44,46]$.

Some features and criteria of an effective CIRS process $[11,36]$ and generic positive factors of CIRS [13, 16] were described in detail, too.

\section{CIRS and positive trends}

In a survey [27], 100\% of medical professionals and $100 \%$ of nurses specified sustainable corrections for their organization based on CIRS reports, whereas $50 \%$ of the medical-technical staff indicated no improvements due to CIRS. It was found that CIRS is important in creating a positive error-safety culture, in detecting weak points, and in analysing necessary system changes [27]. CIRS can provide sufficient qualitative data for detecting critical system errors in health care institutions and organizations. The CIRS-based data allows the analysis of the current situation and development of possible counterstrategies to positively influence the increase in patient safety [6]. In an Australian study, it was found that system changes based on CIRS reduce the numbers of future adverse events [48]. Other positive trends were described elsewhere [49-51]. Certain measures were given by Leape and Berwick [2] and Merkle [29].

\section{Further cognition}

Several issues of further importance were found: (i) technical measures derived from incident reports may lead to new error resources [50]; (ii) the probable importance of national incident-reporting systems relevant to anaesthesia [31]; (iii) an inflationary push of CI-reporting systems without a sound comprehension or planning (see Ramanujam et al. [30] for an example in medication); 
(iv) ineffectiveness in dealing with CI reports [4]; (v) the relationship between CIRS and related reporting systems with organizational quality management [52]; (vi) complementary approaches of CIRS $[5,6,8,16,26]$; and (vii) the dispute on the relationship between incident report frequency and patient safety $[8,12,15,17,18,20,21,25,53]$.

\section{Discussion}

In recent years, CIRS and related reporting systems (there are three distinct reporting systems in European hospitals, at least: Doupi [54]) have become an essential prerequisite for many health care organizations [54]. The implementation of CIRS is an important undertaking for hospitals as it is expected to contribute significantly to the reduction of clinical risk. With respect to Austria, the integration of risk management in quality management systems (ISO 9001:2015) and in the national law of Austria (Ministerialentwurf 143/ME XXV, $\$ 4$ (15)) necessitates the development of consistent risk management practices in clinical settings.

The purpose of this work was a literature search to provide an overview on CIRS and its utility in clinical risk management and the relationship between CIRS adoption and patient safety. Application of predetermined exclusion criteria and inclusion criteria led to a core set of articles consisting of 36 studies, 6 reviews, and 14 specialist books or technical contributions. Available data confirm a positive relationship between the utilization of CIRS and an increase in patient safety. A 'probable' positive effect of incident reporting on patient safety was established, but CIRS must be planned and implemented in a systematic way.

Core elements of a well-functioning CIRS are feedback, involvement of the whole staff including top management commitment, and the integration of CIRS in both risk and quality management. It is important to illustrate the advantages of a CIRS system for a transparent risk reduction process for the benefit of the patients (and, of course, for the clinical staff at all hierarchical levels).

Anonymity and incentives play a pivotal role in maintaining incident reporting, too. Training of staff and transparency are very often mentioned throughout the sources which came under scrutiny. A well-planned and implemented CIRS may improve organizational errorreporting culture, learning processes, and overall safety. In practical terms, the establishment of a skilled risk manager position is highly recommended to point out the importance of CIRS and to encourage recognition and acceptance for a successful CIRS implementation. The risk manager has to find ways to convince members of the top management and clinical staff members to contribute to risk minimization and patient safety through CI reporting. Conversely, the risk manager needs the support of top management.
A CIRS not supported by managers of the higher organizational levels will be implemented with trouble and will not produce any quantifiable improvement. It should be also noted that key figures or indicators, which can be often found in literature on CIRS, are probably helpful in terms of process steering in health care organizations, but do not improve patient safety.

In addition, several limitations have been found:

- Because of the chosen method, there may be restrictions in validity imposed by the selection criteria and by the restricted number of pages.

- There are no pooled results due to the nonavailability of intervention studies as a result of the predetermined selection criteria.

- Due to the heterogeneity of incident-reporting systems and the inclusion of similar designations such as near misses and CI, interpretations in literature reports often diverge.

- Because no fee-based databases were used in the literature search, there might be further restrictions in validity.

- There is an unmet need for a confirmation of the effectiveness of CIRS in clinical practice. This would provide another starting point for a Ph.D. thesis.

\section{Conclusion}

The literature search conducted in this study revealed unambiguously that incident reporting in hospitals is highly variable. This can be attributed to the nonavailability of a global standard, norm, or certification guidance specific for CI. In practical terms, it seems that CIRS (or similar reporting systems as seen in Doupi [54] and in Levtzion-Korach et al. [26]) is often implemented in a more intuitive manner instead of in a systematic way. Nevertheless, CIRS was found to have a positive impact on safety culture in most cases, although description or analysis of the factual relationship between the reporting system and patient safety remains vague. When applied in an optimized manner, CIRS induces positive changes such as the adaption of processes [20, $53]$, awareness of risk $[10,16,19,53]$, and 'near misses' $[19,20]$.

\section{Abbreviations \\ Cl: Critical incident(s); CIRS: Critical Incident Reporting System; ICU: Intensive care unit; N: Number (statistics); SOP: Standard operating procedure}

\section{Acknowledgements}

Without the assistance of the Association for Quality and Safety in Health Care (ASQS) this article would not have been feasible.

Funding

Not applicable.

Availability of data and materials

Please contact the authors for data requests. 


\section{Authors' contributions}

WP designed the study, collected the data, and had the main responsibility for data analysis with supervision from HB. Both authors drafted the manuscript and have read and approved the final version of the manuscript.

\section{Ethics approval and consent to participate}

There was neither ethics approval nor consent to participate necessary for this literature-based research. This article has not been published or sent to submission before.

\section{Consent for publication}

Not applicable.

\section{Competing interests}

The authors declare that they have no competing interests.

\section{Publisher's Note}

Springer Nature remains neutral with regard to jurisdictional claims in published maps and institutional affiliations.

\section{Author details}

'Neurologisches Rehabilitationszentrum Rosenhügel, Rosenhügelstraße 192 a, 1130 Wien, Austria. ${ }^{2} \mathrm{FH}$ Campus Wien - University of Applied Sciences, Favoritenstraße 226, 1100 Wien, Austria.

\section{Received: 6 March 2017 Accepted: 25 July 2017}

Published online: 07 August 2017

\section{References}

1. Institute of Medicine (IOM). To err is human, Building a safer health system. Washington DC: National Academies Press; 2000. p. 27-34.

2. Leape Lucian L, Berwick Donald M. Five years after to err is human — what have we learned? J Am Med Assoc. 2005;293(19):2384-90. https://doi.org/10. 1001/jama.293.19.2384

3. Sendlhofer G, Leitgeb K, Kober B, Brunner G, Kamolz LP. The evolution of the Critical Incident Reporting System in an Austrian university hospital. Z Evid Fortbild Qual Gesundhwes. 2016;114:48-57.

4. Rose N, Germann D. Resultate eines krankenhausweiten Critical Incident Reporting System (CIRS). Gesundheitsökonomie Qualitätsmanagement. 2005;10(2):83-9. https://doi.org/10.1055/s-2005-858053

5. de Feijter JM, de Grave WS, Muijtjens AM, Scherpbier AJ, Koopmans RP. A comprehensive overview of medical error in hospitals using incidentreporting systems, patient complaints and chart review of inpatient deaths. PLoS One. 2012;7(2):e31125. https://doi.org/10.1371/journal.pone.0031125

6. Desikan R, Krauss MJ, Dunagan WC, Rachmiel EC, Bailey T, Fraser VJ. Reporting of adverse drug events: examination of a hospital incident reporting system. Adv Patient Saf. 2005:1:145-60.

7. Evans SM, Berry JG, Smith BJ, Esterman A, Selim P, O'Shaughnessy JO, Dewit M. Attitudes and barriers to incident reporting: a collaborative hospital study. Qual Saf Health Care. 2006;15(1):39-43.

8. Hutchinson A, Young TA, Cooper KL, Mcintosh A, Karnon JD, Scobie S, Thomson RG. Trends in healthcare incident reporting and relationship to safety and quality data in acute hospitals: results from the National Reporting and Learning System. Qual Saf Health Care. 2009;18:5-10. http:// dx.doi.org/10.1136/qshc.2007.022400

9. Gunkel C, Rohe J, Heinrich AS, Hahnenkamp C, Thomeczek C. CIRS Gemeinsames Lernen durch Berichts- und Lernsysteme. In: Herbig N, Poppelreuter S, Thomann H, editors. Qualitätsmanagement im Gesundheitswesen. 31. Aktualisierung. Köln: TÜV Media; 2013. p. 1-46, Anhang. Berlin: ÄZQ; 2013. (äzq Schriftenreihe; 42). https://doi.org/10.6101/ azq/000161.

10. Spigelman AD, Swan J. Review of the Australian Incident Monitoring System. ANZ J Surg. 2005;75(8):657-61. https://doi.org/10.1111/j.1445-2197. 2005.03482.x

11. Gluyas H, Morrsion P. Patient safety—an essential guide. Hampshire: Palgrave; 2013. ISBN: 9780230354968

12. Tereanu C, Minca DG, Costea R, Grego S, Ravera L, Pezzano D, Vigano P. ExpIR-RO: a collaborative international project for experimenting voluntary incident reporting in the public healthcare sector in Romania. Iran J Public Health. 2011;40(1):22-31.
13. Nakajima K, Kurata Y, Takeda H. A web-based incident reporting system and multidisciplinary collaborative projects for patient safety in a Japanese hospital. Qual Saf Health Care. 2005;14(2):123-9. http://dx.doi.org/10.1136/ qshc.2003.008607

14. Dinkel M., Eiche J, editors. Praktisches Risikomanagement. Risk management in clinical practice. Bad Neustadt/Saale; 2005. http://campus-nes.de/ fileadmin/user_upload/Prakt_Risikomanagement.pdf (8 Jun 2017).

15. Nuckols TK, Bell DS, Liu H, Paddock SM, Hilborne LH. Rates and types of events reported to establish incident reporting systems in two US hospitals. Qual Saf Health Care. 2007;16:164-8. http://dx.doi.org/10.1136/qshc.2006. 019901

16. Panzica M, Krettek C, Cartes M. Clinical Incident Reporting System als Instrument des Risikomanagements für mehr Patientensicherheit. Unfallchirurg. 2011;114:758-67. http://dx.doi.org/10.1007/s00113-011-2027-5

17. Hübler M, Möllemann A, Eberlein-Gonska M, Regner M, Koch T. Anonymes Meldesystem kritischer Ereignisse in der Anästhesie. Der Anästhesist. 2006; 55:133-41. https://doi.org/10.1007/s00101-005-0926-y

18. Heideveld-Chevalking AJ, Calsbeek H, Damen J, Gooszen H, Wolff AP. The Impact of a standardized incident reporting system in the perioperative setting. A single center experience on 2.563 'near-misses' and adverse events. Patient Saf Surg. 2014;8(46):1-10. https://doi.org/10.1186/s13037-0140046-1

19. Gupta S, Naithani U, Brajesh SK, Pathania VS, Gupta A. Critical Incident Reporting in anaesthesia: a prospective internal audit. Indian J Anaesth. 2009;53(4):425-33. http://www.ijaweb.org/text.asp?2009/53/4/425/60313

20. Schildmeijer K, Unbeck M, Muren O, Perk J, Härenstam KP, Nilsson L. Retrospektive record review in proactive patient safety work: identification of no-harm incidents. BMC Health Serv Res. 2013;13:282. https://doi.org/10 1186/1472-6963-13-282

21. Kim C-H, Kim M. Defining reported errors on web-based reporting system using ICPS from nine units in a Korean university hospital. Asian Nurs Res. 2009:3(4):167-76. https://doi.org/10.1016/S1976-1317(09)60028-1

22. Valentin A, Capuzzo M, Guidet B, Moreno R, Metnitz B, Bauer P, Metnitz P. Errors in administration of parenteral drugs in intensive care units: multinational prospective study. BMJ. 2009;338 https://doi.org/10.1136/ bmj.b814. Accessed 8 June 2017.

23. Cousins DH, Gerrett D, Warner B. A review of medication incidents reported to the National Reporting and Learning System in England and Wales over 6 years (2005-2010). Br J Clin Pharmacol. 2012;74(4):597-604. https://doi. org/10.1111/j.1365-2125.2011.04166.x

24. Brinkrolf P, Prien T, Van Aken H. Medication errors-a systematic analysis of CIRS-AINS reports. Anästh Intensivmed. 2013:54:126-32.

25. Westbrook Jl, Li L, Lehnbom EC, Baysari MT, Braithwaite J, Burke R, Conn C, Day RO. What are incident reports telling us? A comparative study at two Australian hospitals of medication errors identified at audit, detected by staff and reported to an incident system. Int J Qual Health Care. 2015;27(1): 1-9. https://doi.org/10.1093/intahc/mzu098

26. Levtzion-Korach O, Frankel A, Alcalai H, Keohane C, Orav J, Graydon-Baker E, Barnes J, Gordon K, Puopulo AL, Tomov El, Sato L, Bates DW. Integrating incident data from five reporting systems to assess patient safety: making sense of the elephant. Jt Comm I Qual Patient Saf. 2010:36(9):402-10. AP1-AP18

27. Orlicek F. Kann CIRS die Sicherheitskultur verbessern? Saarbrücken: VDM; 2011. ISBN: 10:3639349342

28. Weimann E, Weimann P. Das Swiss Cheese Model als "critical incident reporting system" zur Risikoreduzierung und Erhöhung der Patientensicherheit in Klinik und Praxis. Pneumologe. 10:201-4. https://doi. org/10.1007/s10405-013-0687-2

29. Merkle W, editor. Risikomanagement und Fehlervermeidung im Krankenhaus. Berlin Heidelberg: Springer; 2014. ISBN: 978-3-642-38045-7

30. Ramanujam R, Keyser D, Sirio C, Thompson DN. Inside the black box: the use of voluntarily reported incident data. 2008. https://www.researchgate. net/publication/228490683_Inside_the_black_box_The_use_of_voluntarily_ reported_incident_data (8 Jun 2017).

31. Reed S, Arnal D, Frank O, Gomez-Arnau I, Hansen J, Lester O, Mikkelsen K, Rhaiem T, Rosenberg P, St. Pierre M, Schleppers A, Staender S, Smith F. National critical Incident reporting systems relevant to anaesthesia: a European survey. Br J Anaesth. 2014;112:546-55. https://doi.org/10.1093/ bja/aet406

32. St. Pierre M. Safe patient care-safety culture and risk management in otorhinolaryngology. Laryngorhinootologie. 2013;92:23-32. https://doi.org/ 10.3205/cto000101 
33. Wong J, Beglaryan $\mathrm{H}$. Strategies for hospitals to improve patient safety. The Change Foundation; 2004. http://www.dphu.org/uploads/attachements/ books/books_331_0.pdf (8 Jun 2017).

34. Pawlowsky $P$, Mistele $P$, editors. Hochleistungsmanagement Leistungspotenziale in Organisationen gezielt fördern. Wiesbaden: Gabler; 2008. ISBN: 978-3-8349-9878-1

35. Bocion C, Sennhauser FH, Frey B. Critical Incident Monitoring in schweizerischen Intensivstationen Verbreitung, Einstellung und Faktoren, welche die Meldehäufigkeit beeinflussen. Schweiz Ärzteztg. 2006;87:886-93.

36. Rose N, Hess U. Melden von Near Misses im Krankenhaus. Klinisches Risikomanagement in der Onkologie. Onkologe. 2008;14(7):721-6. http://dx. doi.org/10.1007/s00761-008-1402-5

37. Kaloud H. Das fehlermelde- und Präventionssystem "CIRPS". Österr Pflegezeitschrift. 2010;2:12-6. http://www.patientenanwalt.com/ download/Expertenletter/Gesundheitswesen/Fehlermeldesystem_CIRPS_ Handbuch_AUVA_Herbert_Kaloud_Expertenletter_Gesundheitswesen.pdf (8 Jun 2016)

38. Herzer KR, Mirrer M, Xie Y, Steppan J, Li M, Jung C, Cover R, Doyle PA, Mark $\sqcup$. Patient safety reporting systems: sustained quality improvement using a multidisciplinary team and "Good Catch" awards. Jt Comm J Qual Patient Saf. 2012;38(8):339-47.

39. Steyrer J, Schiffinger M, Huber C, Valentin A, Strunk G. Attitude is everything? The Impact of workload, safety climate, and safety tools on medical errors: a study of intensive care units. Health Care Manag Rev. 2013; 38(4):306-16. https://doi.org/10.1097/HMR.0b013e318272935a

40. Khorsandi M, Skouras C, Beatson K, Alijani A. Quality review of an adverse incident reporting system and root cause analysis of serious adverse surgical incidents in a teaching hospital of Scotland. Patient Saf Surg. 2012; 6(21):1-6. https://doi.org/10.1186/1754-9493-6-21

41. Klauber J, Geraedts M, Friedrich J, Wasem J, editors. Krankenhaus-Report. Stuttgart: Schattauer; 2014. ISBN: 978-3-7945-2972-8

42. Hoffmann B, Beyer M, Rohe J, Gensichen J, Gerlach FM. Reporting and learning system for general practice. Qual Saf Health Care. 2008;17:307-12. https://doi.org/10.1136/qshc.2006.018440

43. Benn J, Koutantji M, Wallace L, Spurgeon P, Rejman M, Healey A, Vincent C. Feedback from incident reporting: information and action to improve patient safety. Qual Saf Health Care. 2009;18(1):11-21. http://dx.doi.org/10.1136/qshc.2007.024166

44. Mahajan RP. Critical incident reporting and learning. Br J Anaesth. 2010; 105(1):69-75. https://doi.org/10.1093/bja/aeq133

45. Barach P, Small SD. Reporting and preventing medical mishaps: lessons from non-medical near misses reporting systems. BMJ Qual Saf. 2000; 320(7237):759-63. https://doi.org/10.1136/bmj.320.7237.759

46. Kaldijan LC, Jones EW, Wu BJ, Forman-Hoffmann VL, Levi BH, Rosenthal GE. Reporting medical errors to improve patient safety. A survey of physicans in teaching hospitals. Arch Intern Med. 2008;168(1):40-6. https://doi.org/10. 1001/archinternmed.2007.12

47. Koebberling J. Lernen aus CIRS - eine Kasuistik. Med Klin. 2008;103(1):1-9. https://doi.org/10.1007/s00063-008-1008-0

48. Wolff AM, Bourke J, Campbell IA, Leembruggen DW. Detecting and reducing hospital adverse events: outcomes of the Wimmera clinical risk management program. Med J Aust. 2001;174(12):621-5.

49. Pham JC, Girard T, Pronovost PJ. What to do with healthcare incident reporting systems. J Public Health Res. 2013;2(e27):154-9. http://dx.doi.org/ 10.4081/jphr.2013.e27

50. Wan S, Siow YN, Lee SM, Ng A. Audits and critical incident reporting in paediatric anaesthesia: lessons from 75.331 anaesthetics. Singapore Med J. 2013;54(2):69-74. doi:10.11622/smedj.2013027.

51. Schreiner-Hecheltjen, Josefa. Qualitätsmanagement und Qualitätssicherung in der Medizin. Aus der Praxis für die Praxis. 2015. ISBN: 978-3-643-12637-5.

52. Takeda H, Matsumura Y, Nakajima K, Kuwata S, Zhenjun Y, Shanmai J, Qiyan Z, Yufen C, Kusuoka H, Inoue M. Healt care quality management by means of an incident report system and an electronic patient record system. Int J Med Inform. 2003;69(2-3):285-93. https://doi.org/10.1016/S13865056(03)00010-8

53. Anderson JE, Kodate N, Walters R, Doods A. Can incident reporting improve safety? Healthcare practitioners views of the effectiveness of incident reporting. Int J Qual Health Care. 2013;25(2):141-50. https://doi.org/10.1093/ intqhc/mzs081
54. Doupi P. National reporting systems for patient safety incidents. A review of the situation in Europe. In: Report, 13/2009. ISSN: 1798-0089. Jyväskylä: National Institute for Health and Welfare; 2009.

55. Moss SJ, Embletion ND, Fenton AC. Towards safer neonatal transfer: the importance of critical incident review. Arch Dis Child. 2005;90:729-32. http://dx.doi.org/10.1136/adc.2004.066639

56. Aktionsbündnis Patientensicherheit. Empfehlungen zur Einführung von Critical Incident Reporting Systemen (CIRS). 1. Aufl ed. Herdecke: Universität Witten; 2007. Witten, 2007. http://www.aps-ev.de/wp-content/uploads/2016/ 08/07-07-25-CIRS-Handlungsempfehlung.pdf

57. Hoffinger G, Horstmann R, Waleczek H. Das Lernen aus Zwischenfällen lernen: Incident Reporting im Krankenhaus, Hochleistungsmanagement. München: Gabler; 2008. p. 207-24.

58. Köebberling J. Das Critical Incident Reporting System (CIRS) als Mittel zur Qualitätsverbesserung in der Medizin. Med Klin. 2005;100(3):143-8. https:// doi.org/10.1007/s00063-005-1011-7

59. Levinson DR. Hospital incident reporting systems do not capture most patient harm. US-Department of Health and Human Services, Office of Inspector General. 2012. https://oig.hhs.gov/oei/reports/oei-06-09-00091.pdf (8 Jun 2017).

60. Rohe J, Heinrich AS, Hahnekamp C, Gunkel C, Thomeczek C. Erfahrungen mit Critical Incident Reporting-Systemen. Z Evid Fortbild Qual Gesundheitswes. 2014;108(1):49-50. http://dx.doi.org/10.1016/j.zefq. 2014.01.006

61. Rohe J, Thomeczek C. Aus Fehlern lernen: Risikomanagement mit Fehlerberichtssystemen. Das Wissenschaftsforum Gesund Ges. 2008; 8(1):18-25.

62. Waterson P. Patient Safety Culture, Theory, methods and application. Farnham: Ashgate; 2014. ISBN-10: 1409448142

63. Zapp W, editor. Risikomanagement in Stationären Gesundheitsunternehmungen. Grundlagen, Relevanz und Anwendungsbeispiele aus der Praxis. Heidelberg: Medhochzwei Verlag GmbH; 2011. ISBN: 978-3-86216-062-4

\section{Submit your next manuscript to BioMed Central and we will help you at every step:}

- We accept pre-submission inquiries

- Our selector tool helps you to find the most relevant journal

- We provide round the clock customer support

- Convenient online submission

- Thorough peer review

- Inclusion in PubMed and all major indexing services

- Maximum visibility for your research

Submit your manuscript at www.biomedcentral.com/submit
) Biomed Central 